\title{
An Analysis of the Distribution of Student Financial Aid and Social Justice in China: a Quantitative Approach
}

\author{
Xiehua Zou \\ Department of Public Administration \\ China University of Geosciences (Wuhan) \\ 388 Lumo Road, Wuhan, Hubei Province 430074, China \\ E-mail: xiehua.zou@gmail.com
}

The research is conducted during the author's PhD study at King's College London, which was jointly financed by K.C. Wong Education Foundation, China Scholarship Council and British Foreign \& Commonwealth Office.

\begin{abstract}
The Chinese government's stated objective of student financial aid (SFA) policy is to help students from low-income families to access higher levels of education. This article first explores the possible associations between the distribution of SFA and students' various demographic and academic backgrounds. Then it presents the findings regarding students' experiences of the current SFA policy, according to the questionnaire data. Based on these findings, a path analysis is used to construct a quantitative model to explain what factors shape the distribution of SFA. This model to some extent, if not fully, explains the patterns of SFA distribution evident from the data; it also provides important implications for further investigation.
\end{abstract}

Keywords: Chinese student financial aid policy, Social justice, Quantitative methods

\section{Introduction}

In line with the global trend, China has been reforming its higher education (HE) system in the direction of sharing cost between government (or taxpayers) and individuals, and establishing student financial aid (SFA) schemes to maintain accessibility, especially for low-income and socially disadvantaged students (Johnstone, 1998; Shen and Li, 2003; Finnie, 2004). In the past two decades, most research studies on Chinese SFA policy have focused on changes in the types of SFA provided, increasing governmental investment on SFA schemes, and more beneficiaries of SFA. As a result, little is known about who have actually obtained SFA money and the social process that SFA money has been distributed.

In this article I concentrate on the impact of SFA distribution according to what I observed in research sites and establish how far these are consistent with the Chinese government's declared aim of establishing a just SFA system to help students from low-income families access higher levels of education. In particular I want to focus on the provision of SFA in terms of social factors and academic performance, and students' experience and attitudes toward the current SFA system in China. By shedding new light on these under-researched aspects of Chinese higher education (HE) policy and practice, I hope to make a contribution to thinking about possible future directions for the promotion of more socially just SFA policies and practices.

\section{Method}

China has one of the world's largest higher education systems in terms of both the number of institutions and the size of enrolment (Mohrman, 2003). While it is impossible to include all the institutions in a single study, a practical solution is to focus on a manageable sample based on a certain set of criteria. With this in mind, this article draws substantially on the empirical evidence from questionnaire surveys conducted in one university in central China during a field trip which involved both a questionnaire survey and semi-structured interviews. Where necessary, interview data are used to triangulate with the quantitative data. However, the analysis in this article is primarily quantitative.

180 undergraduates and 60 senior high school students were invited to participate in the questionnaire survey. The participating HE institution is the China University of Resources (CUR) (Note 1). The questionnaires were designed and field-tested at an earlier stage among a small group of students through email. In the light of the field-testing, the 
questionnaires were revised to clarify ambiguities and amended to take account of omissions and unanticipated answers in multiple choice and ranking questions. The questions in the questionnaires reflected a number of key areas of enquiry: personal information including gender, socio-economic background, place of residence, and academic performance; personal experience of, and knowledge about SFA; perceptions of the role of SFA and attitudes towards the current SFA policies and practices. Finally the questionnaire also sought to find out possible reasons why students qualified to attend university did not pursue a university education.

Of the 180 first-year undergraduates from CUR who were sent questionnaires, 168 (93\%) returned their completed questionnaires. No further efforts were made to contact those who did not return their questionnaires, due to time constraints.

I first used a Chi-square significance test to investigate whether there is any association between independent variables (socio-economic background, academic performances, etc.) and the distribution of SFA in CUR. The Chi square analysis indicates some possible trends in the data. Since these variables are interwoven, I took a further step in the analysis by using path analysis. Hypothesized causal connections between sets of variables were drawn from the previous Chi-square tests and relevant literature, and tested within the sample of CUR. The analysis was conducted by a computer statistical package (SPSS) and the result is represented by a path diagram. The analysis process is summarized in Figure 1.

\section{The Distribution of SFA at CUR}

\subsection{Gender}

All Chinese universities are co-educational. At CUR, female respondents account for $34.5 \%$ of the students (see Table 1).

In looking at the distribution by gender, this survey indicates that SFA slightly favors female students, as Table 2 shows that $72 \%$ of male students obtained at least one form of SFA whereas a larger proportion, $88 \%$, of females were funded by SFA. There is a significant association between the provision of SFA and gender with Chi square $=5.02, \mathrm{df}=1, \mathrm{p}=$ 0.025 (Note 2). Thus it is a preliminary hypothesis that gender might affect the SFA distribution in CUR.

Hypothesis 1: Female students are more likely to obtain SFA.

Table 3 is based on the distribution of all the five types of SFA in terms of gender. Chi square tests show that gender is a significant factor in the distribution of scholarships $(\mathrm{p}=0.002)$.

Hypothesis 2: Female students are more likely to obtain scholarships.

\subsection{Ethnicity}

China is a multi-ethnic country comprising 56 recognized ethnic groups. According to the latest Population Census in 2002, Han people form $91.6 \%$ of the total Chinese population whereas non-Han (minorities) comprise $8.4 \%$. It is a coincidence that the sample in this study comprises $91.6 \%$ (152) Han and $8.4 \%$ (14) non-Han respectively (3 respondents refused to list their ethnicity). Of the minority respondents, $71.4 \%$ (10) were funded by SFA which is relatively lower than the Han group at 78\% (see Table 7). More specifically, of minority students, none received a grant, $5(35 \%)$ were awarded scholarships, $2(14 \%)$ worked for study and $3(21.4 \%)$ received student loans. However, a Chi square test shows no significant association between ethnicity and SFA distribution. Meanwhile, a significant relationship was found between the provision of scholarship and ethnicity (Chi square $=8.03, \mathrm{df}=1, \mathrm{p}=.005$ ). No significant associations were found between the provision of the other forms of SFA and ethnicity. Therefore, we may construct a preliminary hypothesis that:

Hypothesis 3: Minority students are less likely to obtain scholarship.

Given that most minority people live in the economically less developed west and southwest of China, and higher education is in general a heavier burden to them, the finding in the practice of SFA in CUR suggest that why less minority students get SFA and how they can survive their university without any financial supports still remain a matter of concern.

\subsection{Place of Origin}

In this study the respondents' home residences are classified as rural and urban based on the Registered Resident policy (Hukou), by which Chinese people are officially divided into rural and urban residents by the government. According to the official statistics, more than $64 \%$ of the Chinese population is rural (National Bureau of Statistics, 2005).

The bulk of the respondents in this survey $(114,67.9 \%)$ were from rural areas, $53(31.5 \%)$ were from urban locations and one respondent did not to answer. Of the rural students, $92(80 \%)$ received at least one type of SFA. Meanwhile 36 $(69 \%)$ urban students received SFA. Chi square tests show no significant relationship between place of origin and provision of SFA. The survey also shows that $13(11.4 \%)$ of rural and 1 of urban (1\%) students received grants; 73 
(64\%) rural and $33(62 \%)$ urban students were awarded scholarships; 24 (39\%) rural students worked for study whereas only $3(5 \%)$ of the urban students worked; $26(22.8 \%)$ rural and $4(7 \%)$ urban students received a student loan. A Chi square test shows that place of origin is a significant factor in the distribution of work-study opportunities $(\mathrm{p}=0.038)$. Therefore, a preliminary hypothesis is

Hypothesis 4: Rural students are more likely to obtain work-study opportunities.

\subsection{Parental Occupation}

Parental occupation is another factor which may influence the SFA distribution (Callender and Willkinson, 2005; Lau, 2001). Based on some previous studies (e.g. Lu,2002), in this study I classify the common careers in current China into: public administrator, e.g. high-rank officials in government and armed forces; capitalist, e.g. those owning businesses which employ more than 8 persons; manager and professional, e.g. managers, doctors, lawyers, teachers, technicians, engineers, journalists; the petit bourgeois, e.g. those self-employed or owning small businesses which employ less than 8 persons, shopkeepers, grocers, garage owners, etc; routine white collar workers e.g. clerical workers, shop assistants, low-rank officials in government and armed forces; farmers; manual workers, e.g. workers in manufacturing, plumbers, bus and taxi drivers,; and those who are unemployed.

Table 5 provides an account of the SFA distribution by parental occupation. Of the 168 students from CUR, 161 provided their parent's occupations. No significant association was found by a Chi square test between parental occupation status and the distribution of SFA in CUR, but there are significant associations between parental occupation and the distribution of grant $(\mathrm{p}=0.044)$ and student loans $(\mathrm{p}=0.08)$. Thus I hypothesize accordingly:

Hypothesis 5: Students with lower parental occupational status are more likely to receive grants and student loans.

Over $65 \%$ of them came from farmers' and manual workers' families and some of their parents were unemployed. The survey shows that $83 \%$ of these students were funded by SFA schemes. Since these groups of people are usually at the bottom of Chinese society in terms of income, how they afford the more and more expensive HE without any SFA triggered my interest. Therefore, I invited some of these students to participate in my interviews. Another figure in Table 5 , which might be a reason to identify and examine the SFA selection criteria that are used in practice, is the high percentage of students from public administrator's families who were funded by SFA schemes (83\%). Obviously, in most cases, these students are not needy. So why can so many of them get SFA? Is it because their parents are influential people or because of some other reason? So far the answers are still largely unknown. And I will be investigating these questions using interviews.

\subsection{Income}

The current study classifies the income groups into the lowest (under 2,400 Chinese Yuan per year), low (between 2,400 Yuan and 12,000 Yuan per year), medium (12,001 Yuan to 60,000 Yuan per year) and high (higher than 60,000 Yuan), which is based on previous researches on social stratification in China (e.g. Lu, 2002), and the official statistics on incomes of Chinese people (National Bureau of Statistics, 2003).

Table 6 shows the detailed income groups in the student sample. Of the respondents, 6 did not answer and 29 answered that they did not know their family incomes. More than half of those who said they knew their family incomes (53\%) came from low-income families ( $13.7 \%$ and $39.3 \%$ come from lowest and low-income families respectively), whereas $41(24.4 \%)$ were from middle income families and $3(1.8 \%)$ were from high-income families. Table 6 also shows that $17(74 \%)$ of students from the lowest income families were funded by SFA, whereas $50(74 \%), 34(83 \%)$ and $2(66.7 \%)$ of the low, medium and high income students respectively received SFA. A Chi square test shows no significant relationship between income and the provision of SFA. However, when all the different kinds of SFA were aggregated, the distributions of grant $(\mathrm{p}=0.019)$, work-study $(\mathrm{p}=0.014)$ and student loan $(\mathrm{p}=0.005)$ relate significantly to the student's household income, which are revealed by Chi square tests. A preliminary hypothesis here is that

Hypothesis 6: Students from lower income group are more likely to obtain grant, work-study and student loan.

As the data indicates, despite the fact that more than half of respondents were funded by SFA schemes, a considerable proportion of low-income students still did not get any SFA in CUR, which suggests that the main objective of SFA which according to the government is to aid needy students is not being fully achieved (MoE, 2002). More specifically, although $53 \%$ of the SFA was received by those who are from low-income families (Table 6), there were still $26 \%$ from very low income families, including $50 \%$ of those without any income, who did not receive any SFA. Interview data with these low-income but unfunded students reveals two possible causes: the first is that the student failed in one of the examinations the previous term and therefore was deprived of the opportunities of applying for SFA; the second is that students could not obtain a "low-income certificate" from their local governments, which is a condition of eligibility for applicants for work-study, tuition waiving, student loans and grants. In addition, students may not have been awarded scholarships if they did not get a good enough result in tests. One reason for not obtaining a "low-income certificate", mentioned by one respondent, is the bad relationship between his family and the chief official of local government 
(Interview with Li, an undergraduate from CUR, 2005).

\subsection{Academic Performance}

The entrance of undergraduates to HEIs in China is based on their scores in the National Matriculation Examination (NME) and also on a quota system. Generally, Chinese universities carry out a policy of "entering with difficulty but graduating easily". The vast majority of students will pass the examinations for graduation relatively easily. Due to this fact, we find only one student in the research who thinks he himself cannot pass most of the examinations (see Table 7).

A Chi square test shows a significant association between academic performance and the distribution of SFA (Chi-square $=17.140, \mathrm{df}=3, \mathrm{p}=.001$ ). Given that one student can get more than one type of SFA, all the 7 "excellent" students who often got 91-100 marks in the exams obtained financial supports. $6(86 \%)$ of them were awarded scholarships, whereas $2(29 \%)$ worked for study, $2(29 \%)$ received student loans and $1(14 \%)$ got grants. Of the 49 students who got 81-90 marks, $42(86 \%)$ were funded by SFA schemes, $4(8 \%)$ got grant, 32(65\%) obtained scholarships $8(16 \%)$ worked for study and $9(18 \%)$ received loans. The largest proportion of respondents got between 71-80 marks $(74,44.6 \%)$. Of these students, 60 (81\%) obtained one kind of SFA, 5 (7\%) got grants, $53(71 \%)$ were awarded scholarships, 13 (17\%) got positions of work-study and $13(17 \%)$ were funded by student loans. Among 33 students who often got 61-70, 17 (51\%) were funded by SFA, 3 (9\%) got grants, 13 (39\%) obtained scholarships, 4 $(12 \%)$ worked for study and $4(12 \%)$ received loans (See Table 11). Chi square tests show that academic performance is a significant factor in the distributions of grant $(\mathrm{p}=0.015)$ and scholarship $(\mathrm{p}=0.011)$ A preliminary hypothesis, therefore, is:

Hypothesis 7: Students who obtain better academic performance are more likely to obtain grants and scholarships.

From the data analysis here, it appears that the students' academic performance has an effect on the distribution of SFA in CUR to some degree. More specifically, the information elicited from the data suggests that those who perform better in academic examinations seem to get more chances to obtain SFA in CUR (Mathematically, $100 \%>86 \%>81 \%>51 \%$, see Table 8). All the students getting the highest scores in examinations claim that they were funded by SFA schemes. The possibilities of those who often get 81-90 and 71-80 are not significantly different. Meanwhile, those who often get 60-70 look much less likely to obtain SFA, since the distribution of SFA in this group of respondents is lower than the average level at $78 \%$. A preliminary hypothesis here could be:

Hypothesis 8 Good academic performance helps to obtain SFA.

With regard to the correlation between social factors and students' academic performance, both Chinese and western research communities suggest there is a connection, to some extent, between them (Shen and Li, 2003; Lau, 2001). However, based on the data collected in CUR in this study, Chi square tests show that there are no significant correlations between the students' socio-economic backgrounds and their academic performance in the sample of CUR.

\subsection{Applied or not}

In this questionnaire survey, I also included a question of whether the respondent applied for SFA or not. By asking this question, I was attempting to provide a general picture of the students' demands for SFA and who demand for it. Furthermore, the responses to this question may indicate whether there is a gap between the students' demand and the current provision of SFA. In addition, whether the respondents applied for SFA may to some extent indicate the intentions of students, which obviously affects the distribution of SFA.

Of all the respondents, 123 (73\%) claimed that they applied for at least one type of SFA, whereas 45 (26\%) claimed they did not apply for any SFA. Table 9 provides a summary of who applied for SFA and who did not. Chi square tests show that no significant differences were found in the responses of different groups of students to the item "I applied for SFA schemes."

With respect to those who did not apply for any SFA, I left an open question in the questionnaire to investigate the reasons for not applying. In this group of respondents, 33\% (15 of 45) did not answer the question "why didn't you apply for SFA?", whereas the rest of them gave various answers. More specifically, 37\% (16 of 45) thought their families could afford their university education, and thus it was not necessary to apply for SFA. $18 \%$ (8) thought there were many other students who might be needier than themselves and they should not compete with these students. $7 \%$ (3) claimed that they did not apply for SFA because they did not know the application procedure. $4 \%$ (2) said they did not apply for SFA just because they would rather "rely on themselves" than "the country". Another 4\% (2) stated the number of SFA awardees was so limited that they were not confident to compete with others. The other reasons why the students did not apply for SFA mentioned by the respondents include the following:

The application costs too much time and energy;

The student could not get a "certificate of low-income", which was necessary for applying for SFA, because of their family's bad relationship with the local government; 
The burden of repayment was too heavy to apply for a student loan;

The student failed once in an academic test;

None of SFA schemes provided enough money.

Table 10 reveals that of those who applied for SFA, $111(90 \%)$ received at least one financial aid. A Chi square test also shows there is a strong association between whether a student applies for SFA and whether $\mathrm{s} /$ he can get it $(\mathrm{p}=.000)$.

However, it is noteworthy, reflecting on the responses from CUR, that 14\% of students who received SFA (18 of 129 ) did not claim that they applied for it. A Chi square test shows that, among the forms of SFA, the distribution of grant is not significantly associated with application. On the face of it, this looks surprising because all the SFA schemes require applications (MoE, 2002; Shen and Li, 2003). The collected quantitative data cannot explain this phenomenon significantly, and therefore it raises a question: "why did some people get assistance without applying for it?" This was explored in interviews which will be analyzed in my following writings.

\subsection{Effects of SFA Policy: Students'Perspective}

One of the purposes of the questionnaire survey was to find out whether the SFA schemes provide enough money for the students to survive. In their responses, 36 (21.4\%) respondents agreed that the SFA covers their tuition costs, whereas 61 (36.3\%) students insisted SFA could only cover their living expenses. Besides, some individual respondents said that SFA could cover both tuition and living expenses; however, this group was not statistically significant. A large proportion of respondents who were funded by student loan (28 of 30, 93.3\%) thought student loans could cover their tuition fees successfully. However, the other kinds of SFA were relatively small. Respectively, the highest amounts of grant, scholarship, and work-study received by the respondents were 700, 6,000 and 1,200 Chinese Yuan annually, and each of these highest amounts was obtained by only one respondent. Meanwhile the average tuition and the average total university cost in CUR are 5,400 and 11,300 Yuan annually respectively.

There is no uniformity in the 124 respondents' opinions about whether they could survive well on the money provided by SFA schemes. $49(39.5 \%)$ think the money is enough, whereas $40(32 \%)$ argued that they did not get sufficient money. Among these satisfied students, a significant proportion $(15,30 \%)$ was funded by student loan, which implies the student loan might be an effective form of financial aid in terms of the amount of money it provides.

More specifically, among those from low-income families, 39\% of them claimed to be satisfied with what SFA provides, whereas $29 \%$ did not. $40 \%$ of rural students agreed that they could survive their university lives on SFA. Meanwhile, those from middle-income families $(30 \%)$ and urban students $(36 \%)$ were less satisfied with the amount that SFA provides. One possible reason for this may be that those from urban and middle income families spend more money on their university lives, demonstrated by investigating the cost of university in this study. In other words, rural and urban students may have different expectations of the amount of money they will get from SFA.

Given that more than $77 \%$ of respondents in CUR received financial support from SFA schemes, about 38\% of them worried about their financial status constantly, according to the survey (Table 11). More specially, all the 7 grantees $(100 \%), 40$ of 107 scholarship awardees (37\%), 6 of 27 working for study (22\%) and 13 of 30 loan receivers (43\%) still worried about their financial status. In addition, it needs to be noted that $79 \%(49)$ of those in trouble with money were from rural areas, which also supports the previous finding that rural students need more help.

Also it is noteworthy that, among those who did not get any financial aids, 32.4\% (12 of 37) of them claimed that they were in financial trouble, whereas $17(46 \%)$ of them felt they could afford university and the other $8(21.6 \%)$ were neutral on this question. However, most students $(74.4 \%)$ insisted on continuing their study in spite of facing the stress of insufficient financing (See Table 12).

While one can argue that the students' academic performances are not necessarily due to their socio- economic backgrounds, the students' low-income statuses to some extent have negative effects on their academic performances. In the current study, 102 of the total 166 respondents agree that they may get better academic results in study if they do not need to worry about their financial status, of which $78(76 \%)$ are from rural areas. The distinction between rural and urban students' reflections can be understood if it is borne in mind that generally rural students are less well off than urban students.

It emerged that the authorities (the government and university) have operated some measures to promote the SFA schemes to undergraduates. This is indicated in Table 14 which shows that about $45.2 \%$ of respondents understand the provision of SFA. Chi square tests indicate that in CUR, there are significant associations between the students' knowledge of SFA provision, their ethnic backgrounds $(\mathrm{p}=.032)$ and their household incomes $(\mathrm{p}=.008)$. Meanwhile, no significant associations were found between knowledge of SFA provision and other independent variables such as academic performance, gender and place of origin. When trying to identify the connections between knowledge of SFA provision and whether the respondents can get SFA, no significant association was reported by a Chi square test. Accordingly, a hypothesis here is: 
Hypothesis 9: Han students and students from lower income families better understand what SFA schemes provide.

Table 14 also shows that more than fifty percent of respondents from CUR do not understand the procedure of applying for SFA. There are significant associations between knowledge of application procedures and students' gender $(\mathrm{p}=.020)$ and places of origin $(\mathrm{p}=.024)$, whereas no significant associations were reported by Chi square tests between other independent variables (academic performance, income, parents' occupation, etc.) and the students' knowledge of application procedures. A Chi square test also indicates there is a strong association between the knowledge of provision and receiving SFA $(\mathrm{p}=.016)$. Among the five forms of SFA, the distribution of student loan significantly associates with the knowledge of procedure $(p=.000)$. Accordingly, preliminary hypotheses are:

Hypothesis 10: Female and rural students understand the SFA application procedure better than other students.

Hypothesis 11: Those who understand the application procedure are more likely to get SFA

Hypothesis 12: Those who understand the application procedure are more likely to get a student loan.

The data reveals that, within the sample of CUR, there is a strong correlation between the students' knowledge of SFA provision and the application procedure $(\mathrm{p}=.000)$. We may assume that students who know what SFA provides are more likely to try to understand the application procedure.

Hypothesis 13: Students who know what SFA provides are more likely to try to understand the application procedure.

The information collected about whether students feel shame about receiving SFA indicates another traditional Chinese viewpoint that intellectuals can be poor in material living but should be rich in spirit. Only $7.2 \%$ of the respondents felt shameful if they had survived on SFA, whereas most students received SFA without any psychological barriers. The cross tabulation analysis also reveals that feeling shame on living on SFA is not a reason for not receiving SFA, since only 2 of those without any SFA feel shame on surviving on SFA (Table 15).

\subsection{Path Analysis}

To provide estimates of the magnitude and significance of cause and effect relationships among variables, I applied a path analysis in this study (Webley and Lea, 1997). A series of assumptions are necessary for using path analysis technique with the appropriate rigor. The first of these assumptions is that all variables are measured in an interval scale (Blalock, 1979; Muijs, 2004; Bento and Bento, 2004; Webley and Lea, 1997). However, most of the variables in this study are measured in either ordinal or nominal. One of approaches to this problem that researchers often use is to "adapt or modify the technique by obtaining interval-like (dummy) variables, e.g. converting nominal variables to yes-no, 0-1; and computing interval correlations" (Blalock, 1979; Bento and Bento, 2004). Therefore, in this study, I recoded all the nominal and ordinal variables as dummy variables and assumed that treating them as if they were interval had not introduced distortions to the computations of the correlation coefficients (Blalock, 1979; Muijs, 2004; Bento and Bento, 2004). The order of variables in the path analysis is based on the hypotheses which were obtained previously.

Based on Hypothesis 1, 8, 9, 10, 11, 13, I firstly constructed an input path diagram to indicate possible connections between student's receiving SFA and the other variables (Figure 2). The arrows in the model indicate expected causal connections between variables and each $\mathrm{p}$ donates a casual path. For example, the model proposes that gender has a direct effect on whether a student can obtain SFA. Meanwhile, an indirect effect of gender on receiving SFA is also proposed: gender affects the students' knowledge of application procedure, which in turn affects the student's receiving SFA. The arrow from e1 donates the amount of variance in receiving SFA that is unexplained by all the considered variables in this model. This error term points to the fact that there are other variables that have an impact on the distribution of SFA, but which are not included in the path diagram (Bryman and Cramer, 2001).

In order to provide estimates of each of the postulated paths, path coefficients are needed to be computed by setting up several equations, which stipulate the structure of hypothesized relationships in a model (Bryman and Cramer, 2001). In this study, four equations can be drawn:

Knowledge of Provision (K1) $=\mathrm{x} 1$ Ethnicity $+\mathrm{x} 2$ Income $+\mathrm{e} 2$

Knowledge of Procedure (K2) $=x 3$ K1 $+x 4$ Gender $+x 5$ Place + e3

Income $=\mathrm{x} 6$ Occupation

Receiving SFA $=x 4$ Gender $+x 3 \mathrm{~K} 2+x 7$ Academic $+x 8$ Application $+\mathrm{e} 1$

The above equations also can be treated as regression equations and all the path coefficients and errors can be computed by conducting regression analysis. The following Figure 3 reports the result of path analysis. In order to compare the overall impact of one variable with the others on whether a student could get SFA, I added the direct effects of a variable to its indirect effects as following:

Total effect of Gender $=\mathrm{p} 1+(\mathrm{p} 2)(\mathrm{p} 8)=-0.1$ 
Total effect of Ethnicity $=(\mathrm{p} 3)(\mathrm{p} 7)(\mathrm{p} 8)=0.002$

Total effect of Parental Occupation $=(\mathrm{p} 10)(\mathrm{p} 4)(\mathrm{p} 7)(\mathrm{p} 8)=-0.001$

Total effect of Income $=(p 4)(p 7)(p 8)=0.005$

Total effect of Place of Origin $=(\mathrm{p} 5)(\mathrm{p} 8)=0.003$

Total effect of Academic Performance $=\mathrm{p} 13=0.178$

Total effect of Application $=\mathrm{p} 6=0.5$

Total effect of Knowledge of Provision= (p7) (p8) $=0.0172$

Total effect of Procedure $=p 8=0.04$ The results of path analysis corroborate the previous hypothesis $1,8,13$. Within the sample of CUR, the student's gender and academic performance are correlated with the distribution of SFA significantly, and the student's knowledge of SFA provision is correlated with the knowledge of application procedure. The total effect of gender, which is negative, means the female students are more likely to obtain SFA schemes in CUR. Compared to social economic factors, academic performance is more influential in the distribution of SFA in CUR. The path analysis also partly corroborates the hypothesis 9 , that the students who come from lower income groups are more likely to understand what SFA schemes provide. In the meantime, the value of $\mathrm{p} 2$ is positive, suggesting that the situation in CUR is contrary to what is suggested hypothesis 10. More specifically, male students in CUR are more likely to understand the SFA application procedure. It is also noteworthy that the effect of application on the distribution of SFA is 0.5 (p6). This corroborates a previous result of cross tabulation analysis that some students in CUR obtain SFA without applying for it. Obviously, it is not in line with what the government declared: "Every eligible student should apply for financial aids via their universities" (MoE, 2002).

The path analysis, to some extent, helps to understand the SFA distribution in the data set. The picture presented here suggests that among the analyzed variables, academic performance plays a more significant role than the others in the SFA distribution in CUR $(\mathrm{p}=0.178)$. In other words, with appropriate caution in exaggerating the significance of each variable, it is a possible argument that SFA selection in CUR seem to be performance-oriented rather than socio-economic-oriented. It is also reinforced by the data from interviews. Many interviewees told me that one of the main reasons they cannot get financial support is their scores in exams, no matter whether they are needy or not. As mentioned above, in CUR, if a student failed in one course during the past year, s/he cannot obtain any SFA except for the student loan.

On the one hand, if students' academic performance is more significant than social factors in the SFA selection, as the analysis which I have made in this chapter suggests, I would argue that this is not because of Chinese government policy, according to the literature review and empirical data collected in CUR. According to the MoE, although scholarships are established to reward those who perform well in academic fields, the other kinds of SFA are to ease the financial burden of poor students (MoE, 2002). On the other hand, I would argue that the reasons why SFA selection in practice is academic performance oriented are plural. One possible reason implied by the interview with SFA administrator in CUR is that the university has not enough money to fund every needy student, although CUR endeavors to establish a large fund for SFA schemes. "There are too many poor students in CUR," said the administrator, "and it is impossible for the university to get enough money to fund every one of them" (Interview with SFA administrator of CUR, 2005). And thus CUR has to make the SFA selection competitive. In addition, a student interviewee mentioned that it was hard to identify the exact financial status of SFA applicants, since nobody went to the applicants' hometown to investigate. According to this informant, another reason why the university selects SFA recipients according to academic performance is just because it is much easier to do so (Shen and Li, 2003; Interview with $\mathrm{Li}$, an undergraduate from CUR, 2005).

However, the results of path analysis do not corroborate the hypothesis 11 and only partly corroborate hypothesis 9 and 10. That is, the student's knowledge of SFA application procedure is not correlated with the distribution of SFA (p8=0.04). It is an interesting puzzle that the students obtained SFA but did not even quite understand the application procedure! Besides, ethnicity does not affect the student's knowledge of SFA provision significantly (p3=0.092). Place of origin does not affect the student's knowledge of SFA application procedure, according to the path analysis ( $\mathrm{p} 5=0.083$ ). It is also noteworthy that the model in the path analysis leaves a relatively big proportion of variation unexplained ( $\mathrm{p} 9=0.664)$.

That some possible connections between variables are not corroborated by the path analysis may be in part because the sample size is not big enough to enable me to infer significant relationships among some of the variables (Muijs, 2004). In part the unconfirmed relationships might result from the respondents' misunderstanding of the questions in the questionnaire. For example, they might understand the "application procedure" as the "selection procedure". Besides, to restate the obvious, while it has much to offer, path analysis has its own limitations (Bryman and Cramer, 2001). In this study, I am forced to rely on the theoretical ideas and "commonsense notions for hypothesizing about the likely 
sequence of the variables" in the SFA distribution in China. It is possible that the conceptions of time ordering were "faulty" and the ensuring path diagram was misleading (Bryman and Cramer, 2001). Therefore, it is quite possible that some relationships do exist among variables, but have not been corroborated or revealed by this analysis. For example, some previous studies suggest that student's receiving SFA and their academic performance are deemed to be correlated (Lau, 2001, Shen and Li, 2003). That is, in Figure 2 and 3, the link between "Academic performance" and "Receiving SFA" is supposed to be indicated by an arrow with two heads. However, since respondents are the first year students, an effect of students' receiving SFA on their academic performances, which may occur in subsequent years, was not revealed by this study.

Another possible reason for the large variance left by the path model is that the model does not include all relevant factors, given that the distribution of SFA in China is very complicated. To identify such factors I have also included some relevant questions in the semi-structured interviews, which are going to be analyzed in my future work.

\section{Some Preliminary Conclusions on the Questionnaire Data}

In this article, I have been attempting to provide a descriptive account of SFA distribution in CUR and students' experience and attitudes towards SFA. In doing so, I examined the aspects of distributional and procedural justice in SFA distribution. The responses of 168 undergraduates from CUR were analyzed. Several findings have emerged from the data.

In terms of distributive justice, despite SFA schemes in CUR benefiting more than $77 \%$ of the respondents, a considerable proportion of needy students still have not been funded. According to the data from CUR, $26 \%$ of the lowest income respondents did not receive any SFA. Responses to the question about the reasons for those who were qualified but did not enter university also imply that the students' low financial status is still an important factor in their decision to withdraw from higher education. One possible reason for this situation, which is suggested by the data, is that SFA selection is academic performance oriented. Yet little is known as to whether there are any factors affecting SFA allocation more significantly than the students' academic performance. We do know it plays a more important role than the socio-economic factors in SFA selection, based on the data analyzed so far. I am not arguing that the criteria of SFA selection should be needs based or performance based. I am saying that the practice in CUR by no means conforms to the "just principle" of the SFA policy which is claimed by the Chinese government as:

"(the government's) aim is to guarantee that every qualified but needy student enter the university and no students quit from university for financial reason... Targeting the needy students, the government endeavors to establish a system of financial aids..." (MoE, 2002)

Considering that the university education is expensive, how students from low-income families survive their university in CUR without any aids remains a matter of concern.

With respect to procedural justice, authorities (the government and HEIs) declared SFA to be open to every student (MoE, 2002). However, it seems difficult to conclude that the implementation of SFA is open and transparent in the light of the lack of knowledge about the SFA procedure claimed by the vast majority of respondents. Furthermore, if the "explicit rule" of SFA selection in CUR is based on economic need, the data analysis in this chapter implies that there might be some "implicit rules" affecting the SFA distribution. One of them may be academic performance, since it accounts for about $16 \%$ of variance in CUR.

In summary, the questionnaire data analysis, on the one hand, generated an overall picture of SFA in CUR, which suggests that SFA schemes have benefited a large portion of students of CUR, whereas there are many students with lower socio-economic status, who are supposed to be funded by SFA, but have not obtained any aids. Furthermore, both Chi square tests and the path analysis imply that the student's academic performance plays a more significant role than social economic factors in the selection of SFA schemes in CUR, which is not in line with the selection principle of SFA declared by the government.

On the other hand, the quantitative analysis in this chapter has encouraged me to try to make the picture clearer through following up with qualitative work. The earlier cross tabulations indicated some possible trends in the SFA distribution in CUR, e.g. Children of public administrators may be disproportionately benefiting from financial aid, as well as that $14 \%$ of students who did not apply for financial aid received it. It is also a puzzle that a relatively large proportion of students did not even know quite what SFA schemes provide and how to apply for them but nevertheless received them. Moreover, in this survey, some respondents mentioned problems getting certificates of low-income, which prevent them from applying for SFA. These trends were not confirmed by the later path analysis, which may be in part because the sample size was not big enough, in part because some of the respondents might have misunderstood the questions in English. Nevertheless, just because I cannot draw firm conclusions about these trends, it does not mean they do not exist.

Moreover, the path analysis left a relatively large proportion of variance unexplained, which implies that some factors are affecting the distribution of SFA but are not covered in the questionnaire. In some cases, the student's subject of 
learning may affect the probability of receiving SFA. It is also possible that, as highlighted in many other relevant researches, some wealthy students "buy" university places, and some influential parents use their social connections to gain places for their children (e.g. Mohrman, 2003). This so called "back door entry" may also exist in the distribution of SFA.

It was with these issues in mind that in-depth semi-structured interviews were conducted afterwards. In my future writings, I will look at the interview data to seek answers to the questions thrown up by the questionnaire data analyzed in this article.

\section{References}

Bento, A. and Bento, R. (2004). The Use of Causal analysis techniques in information systems research: a methodological note, in Journal of Information Management. Vol. XV, No. 3-4, 2004, 45-51.

Blalock, H.M, Jr. (1979). Social Statistics ( $2^{\text {nd }}$ ed.), New York: McGraw-Hill book Company.

Bryman, A and Cramer, D (2001). Quantitative data analysis with SPSS release 10 for Windows. London: Routledge.

Callender, C. and Wilkinson, D (2005). 2002/03 student income and expenditure survey. Research Report No.487, London: London South Bank University.

Finnie, R. (2004). Student financial aid: the roles of loans and grants. Working paper No.37, Queen's University of Queens.

Johnstone, D. B. (1998). The financing and management of higher education: a status report on worldwide reforms. Washington: The World Bank.

Lau, H. (2001). Financing of higher education in Malaysia : an equity and efficiency analysis of student loans and scholarships. Ph.D. Thesis, Institute of Education, London.

Lu, X. (2002). Report on the Stratification in Current Chinese Society. Beijing: Social Science Literature Press.

Ministry of Education (2002). Answers to frequently asked questions about student financial aid policy. Beijing: Higher Education Press.

Mohrman, K. (2003). Higher Education Reform in Mainland Chinese Universities Available: http://www.jyb.com.cn/gb/23/zy/jryw/8.html.

Muijs, D (2004). Doing quantitative research in education with SPSS. London: SAGE.

National Bureau of Statistics, PRC (2003). China Statistical Yearbook 2002. Available: http://www.stats.gov.cn/yearbook2002.html.

National Bureau of Statistics, PRC (2005). China Statistical Yearbook 2004. Available: http://www.stats.gov.cn/yearbook2004.html.

Shen, H and Li, W (2003). A Review of the Student Loans Scheme in China. Bangkok: UNESO.

Webley, P. and Lea, S. (1997). Advanced Statistics: Multivariate Analysis, Available: http:// www.exeter.ac.uk/ SEGLea/multvar2/pathanal.html.

\section{Notes}

Note 1. A pseudonym.

Note 2. The cut-off point for the significance level in this study is 0.05 .

Table 1. Gender distribution of those who returned questionnaires

\begin{tabular}{|l|l|l|}
\hline Gender & Numbers & Percent \\
\hline male & 110 & 65.5 \\
\hline female & 58 & 34.5 \\
\hline Total & 168 & 100.0 \\
\hline
\end{tabular}


Table 2. Gendered Provision of SFA (1)

\begin{tabular}{|l|l|l|l|l|}
\hline \multicolumn{2}{|c|}{} & \multicolumn{2}{|l|}{ gender } & \multirow{2}{*}{ Total } \\
\cline { 3 - 5 } \multicolumn{2}{|c|}{} & male & female & 129 \\
\hline \multirow{2}{*}{ aid } & yes & 78 & 51 & 37 \\
\cline { 2 - 5 } & no & 30 & 7 & 166 \\
\hline Total & 108 & 58 & \\
\hline
\end{tabular}

Table 3. Gendered Provision of SFA (2)

\begin{tabular}{|l|l|l|l|l|}
\hline & grant & scholarship & work-study & Student loan \\
\hline female & & & & \\
\hline male & $2(3 \%)$ & $46(79 \%)$ & $12(20 \%)$ & $8(13 \%)$ \\
\hline
\end{tabular}

Table 4. Aid- ethnicity Cross Tabulation

\begin{tabular}{|l|l|l|l|l|}
\hline \multirow{2}{*}{\multicolumn{2}{|c|}{}} & \multicolumn{2}{|l|}{ ethnicity } & Total \\
\cline { 3 - 5 } \multicolumn{2}{|c|}{} & han & non-han & \\
\hline Receiving aid & yes & 118 & 10 & 128 \\
\cline { 2 - 5 } & no & 33 & 4 & 37 \\
\hline Total & 151 & 14 & 165 \\
\hline
\end{tabular}

Table 5. Parental Occupation and SFA Distribution

\begin{tabular}{|l|l|l|l|}
\hline \multirow{2}{*}{ Parental occupation } & \multicolumn{2}{|l|}{ Receiving aid } & \multirow{2}{*}{ Total } \\
\cline { 2 - 3 } & yes & no & \\
\hline Public administrator & $5(83 \%)$ & 1 & 6 \\
\hline Capitalist & $1(33 \%)$ & 2 & 3 \\
\hline Manager and professional & $16(76 \%)$ & 5 & 21 \\
\hline The petite bourgeois & $9(64 \%)$ & 5 & 14 \\
\hline Routine white collar & $7(64 \%)$ & 4 & 11 \\
\hline Manual worker & $18(78 \%)$ & 5 & 23 \\
\hline Farmer & $65(84 \%)$ & 12 & 77 \\
\hline Unemployment & $4(80 \%)$ & 1 & 5 \\
\hline Others & 1 & 0 & 1 \\
\hline Total & 126 & 35 & 161 \\
\hline
\end{tabular}


Table 6. Income Groups and SFA Distribution

\begin{tabular}{|l|l|l|l|l|}
\hline \multicolumn{2}{|l|}{ Income group/ Annual Income } & Numbers & Percent & SFA received \\
\hline \multicolumn{2}{|l|}{ missing } & 6 & 3.6 & $4(3 \%)$ \\
\hline \multirow{2}{*}{ Lowest income } & no income & 4 & 2.4 & $2(1.5 \%)$ \\
\cline { 2 - 5 } & less than 2400 & 19 & 11.3 & $15(11.6 \%)$ \\
\hline \multirow{2}{*}{ Low income } & $2401-7200$ & 35 & 20.8 & $30(23.3 \%)$ \\
\cline { 2 - 6 } & $7201-12000$ & 31 & 18.5 & $20(15.5 \%)$ \\
\hline \multirow{3}{*}{ Medium income } & $12001-24000$ & 27 & 16.1 & $25(19.4 \%)$ \\
\cline { 2 - 6 } & $24001-60000$ & 14 & 8.3 & $9(7 \%)$ \\
\hline High Income & $60001-120000$ & 3 & 1.8 & $2(1.5 \%)$ \\
\hline don't know & & 29 & 17.3 & $12(9.3 \%)$ \\
\hline Total & & 168 & 100.0 & $129(100 \%)$ \\
\hline
\end{tabular}

Table 7. Marks that the respondents often got in examinations

\begin{tabular}{|l|l|l|l|}
\hline \multicolumn{2}{|l|}{ Performance } & Numbers & Percent (\%) \\
\hline & $91-100$ & 7 & 4.2 \\
\hline & $81-90$ & 49 & 29.2 \\
\hline & $71-80$ & 75 & 44.6 \\
\hline & $60-70$ & 33 & 19.6 \\
\hline & less than 60 & 1 & .6 \\
\hline & Total & 165 & 98.2 \\
\hline & Missing & 3 & 1.8 \\
\hline \multicolumn{2}{|l|}{ Total } & 168 & 100.0 \\
\hline
\end{tabular}

Table 8. Academic Performance and SFA Distribution

\begin{tabular}{|l|l|l|l|l|l|}
\hline \multirow{2}{*}{$\begin{array}{l}\text { Academic } \\
\text { Performance }\end{array}$} & \multicolumn{2}{|l|}{ Receiving SFA } & \multirow{2}{*}{ Total } \\
\cline { 2 - 5 } & Grant & Scholarship & Work-study & Student loan & \\
\hline $91-100$ & $1(14 \%)$ & $6(86 \%)$ & $2(29 \%)$ & $2(29 \%)$ & $100 \%$ \\
\hline $81-90$ & $4(8 \%)$ & $32(65 \%)$ & $8(16 \%)$ & $9(18 \%)$ & $86 \%$ \\
\hline $71-80$ & $5(7 \%)$ & $53(71 \%)$ & $13(17 \%)$ & $13(17 \%)$ & $81 \%$ \\
\hline $60-70$ & $3(9 \%)$ & $13(39 \%)$ & $4(12 \%)$ & $4(12 \%)$ & $51 \%$ \\
\hline Less than 60 & 0 & 0 & 0 & 0 & 0 \\
\hline
\end{tabular}


Table 9. Who did apply for SFA?

\begin{tabular}{|c|c|c|c|c|}
\hline \multirow{2}{*}{\multicolumn{2}{|c|}{ Demographic and academic backgrounds }} & \multicolumn{2}{|c|}{ Applied for SFA } & \multirow{3}{*}{$\frac{\text { Total }}{110}$} \\
\hline & & \multirow{2}{*}{$\begin{array}{l}\text { yes } \\
76(69 \%)\end{array}$} & \multirow{2}{*}{$\begin{array}{l}\text { no } \\
34(31 \%)\end{array}$} & \\
\hline Gender & Male & & & \\
\hline & Female & $47(81 \%)$ & $11(19 \%)$ & 58 \\
\hline \multirow[t]{3}{*}{ Ethnicity } & Han & $114(74.5 \%)$ & $39(25.5 \%)$ & 153 \\
\hline & Non-han & $8(57 \%)$ & $6(43 \%)$ & 14 \\
\hline & Missing & 1 & 0 & 1 \\
\hline \multirow{3}{*}{$\begin{array}{l}\text { Location of } \\
\text { origin }\end{array}$} & Missing & 1 & 0 & 1 \\
\hline & Rural & $88(77 \%)$ & $26(23 \%)$ & 114 \\
\hline & Urban & $34(64 \%)$ & $19(36 \%)$ & 53 \\
\hline \multirow{10}{*}{$\begin{array}{l}\text { Parent's } \\
\text { occupation }\end{array}$} & Public administrator & $4(66.7 \%)$ & $2(33.3 \%)$ & 6 \\
\hline & Capitalist & $2(66.7 \%)$ & $1(33.3 \%)$ & 3 \\
\hline & Manager and professional & $13(62 \%)$ & $8(38 \%)$ & 21 \\
\hline & The petite bourgeois & $9(64 \%)$ & $5(36 \%)$ & 14 \\
\hline & Routine white collar & $7(64 \%)$ & $4(36 \%)$ & 11 \\
\hline & Manual worker & $15(65 \%)$ & $8(35 \%)$ & 23 \\
\hline & Farmer & $64(81 \%)$ & $15(19 \%)$ & 79 \\
\hline & Unemployment & $4(80 \%)$ & $1(20 \%)$ & 5 \\
\hline & Others & $1(100 \%)$ & 0 & 1 \\
\hline & Missing & 4 & 1 & 5 \\
\hline \multirow[t]{9}{*}{ Income } & Missing & 5 & 1 & 6 \\
\hline & No income & $2(50 \%)$ & $2(50 \%)$ & 4 \\
\hline & Less than 2400 & $16(84 \%)$ & $3(16 \%)$ & 19 \\
\hline & $2401-7200$ & $29(83 \%)$ & $6(17 \%)$ & 35 \\
\hline & $7201-12000$ & $20(64.5 \%)$ & $11(35.5 \%)$ & 31 \\
\hline & $12001-24000$ & $19(70 \%)$ & $8(30 \%)$ & 27 \\
\hline & $24001-60000$ & $11(79 \%)$ & $3(21 \%)$ & 14 \\
\hline & $60001-120000$ & $2(67 \%)$ & $1(33 \%)$ & 3 \\
\hline & Don't know & $19(65.5 \%)$ & $10(34.5 \%)$ & 29 \\
\hline \multirow{6}{*}{$\begin{array}{l}\text { Scores in } \\
\text { academic } \\
\text { test }\end{array}$} & $91-100$ & $6(85.7 \%)$ & $1(14.3 \%)$ & 7 \\
\hline & $81-90$ & $41(83.7 \%)$ & $8(16.3 \%)$ & 49 \\
\hline & $71-80$ & $55(73 \%)$ & $20(27 \%)$ & 75 \\
\hline & $60-70$ & $20(61 \%)$ & $13(39 \%)$ & 33 \\
\hline & Less than 60 & 0 & $1(100 \%)$ & 1 \\
\hline & Missing & 1 & 2 & 3 \\
\hline \multicolumn{2}{|l|}{ Total } & 123 & 45 & 168 \\
\hline
\end{tabular}


Table 10. Apply - Aid Cross Tabulation

\begin{tabular}{|l|l|l|l|l|}
\hline \multicolumn{2}{|l|}{} & \multicolumn{2}{l|}{ Received SFA } & \multirow{2}{*}{ Total } \\
\hline \multicolumn{2}{|l|}{} & yes & no & 122 \\
\hline applied & yes & 111 & 11 & 122 \\
\hline & no & 18 & 26 & 44 \\
\hline Total & 129 & 37 & 166 \\
\hline
\end{tabular}

Table 11 . I worry constantly about my finances.

\begin{tabular}{|c|c|c|c|c|}
\hline \multirow{2}{*}{\multicolumn{2}{|c|}{ Students' attitudes }} & \multicolumn{2}{|l|}{ aid } & \multirow[b]{2}{*}{ Total } \\
\hline & & yes & no & \\
\hline \multirow[t]{5}{*}{ worry } & strongly agree & 7 & 2 & 9 \\
\hline & agree & 42 & 10 & 52 \\
\hline & neutral & 32 & 8 & 40 \\
\hline & disagree & 41 & 12 & 53 \\
\hline & strongly disagree & 7 & 5 & 12 \\
\hline \multicolumn{2}{|l|}{ Total } & 129 & 37 & 166 \\
\hline
\end{tabular}

Table 12. Considering leaving university because of financing

\begin{tabular}{|c|c|c|}
\hline & Numbers & Percent \\
\hline Missing & 2 & 1.2 \\
\hline strongly agree & 2 & 1.2 \\
\hline agree & 17 & 10.1 \\
\hline neutral & 17 & 10.1 \\
\hline disagree & 72 & 42.9 \\
\hline strongly disagree & 58 & 34.5 \\
\hline Total & 168 & 100.0 \\
\hline
\end{tabular}

Table 13. I will perform better if I did not worry much about finances.

\begin{tabular}{|l|l|l|l|}
\hline \multirow{2}{*}{} & \multicolumn{2}{|l|}{ aid } & \multirow{2}{*}{ Total } \\
\cline { 2 - 3 } & yes & no & 21 \\
\hline strongly agree & 14 & 7 & 81 \\
\hline agree & 64 & 17 & 31 \\
\hline neutral & 24 & 7 & 26 \\
\hline disagree & 21 & 5 & 6 \\
\hline strongly agree & 5 & 1 & 166 \\
\hline Total & 129 & 37 & \\
\hline
\end{tabular}


Table 14. I know exactly the provision and application procedure of SFA

\begin{tabular}{|l|l|l|l|l|l|l|}
\hline \multirow{2}{*}{} & \multicolumn{2}{|l|}{ Understanding Provision } & \multicolumn{2}{l}{ Understanding Procedure } \\
\cline { 2 - 7 } & Numbers & Rural & Urban & Numbers & Rural & Urban \\
\hline strongly agree & $2(1.2 \%)$ & $1(1 \%)$ & $1(1.8 \%)$ & $5(3 \%)$ & $4(3.7 \%)$ & $1(1.9 \%)$ \\
\hline agree & $74(44.0 \%)$ & $58(51 \%)$ & $16(30.2 \%)$ & $37(22 \%)$ & $35(30.7 \%)$ & $2(3.8 \%)$ \\
\hline neutral & $47(28.0 \%)$ & $32(28 \%)$ & $14(26.4 \%)$ & $37(22 \%)$ & $22(19.3 \%)$ & $15(28.3 \%)$ \\
\hline disagree & $36(21.4 \%)$ & $18(15.7 \%)$ & $18(34 \%)$ & $77(45.8 \%)$ & $45(39.6 \%)$ & $31(58.5 \%)$ \\
\hline strongly disagree & $9(5.4 \%)$ & $5(4.3 \%)$ & $4(7.6 \%)$ & $12(7.1 \%)$ & $8(7 \%)$ & $4(7.5 \%)$ \\
\hline Total & $168(100 \%)$ & $114(100 \%)$ & $53(100 \%)$ & $168(100 \%)$ & $114(100 \%)$ & $53(100 \%)$ \\
\hline
\end{tabular}

Table 15. I feel shame if I survive on SFA.

\begin{tabular}{|l|l|l|l|}
\hline $\begin{array}{l}\text { aid } \\
\text { shame }\end{array}$ & yes & no & Total \\
\hline strongly agree & 1 & 2 & 3 \\
\hline agree & 9 & 0 & 9 \\
\hline neutral & 20 & 6 & 26 \\
\hline disagree & 53 & 16 & 69 \\
\hline strongly disagree & 46 & 13 & 59 \\
\hline Total & 129 & 37 & 166 \\
\hline
\end{tabular}

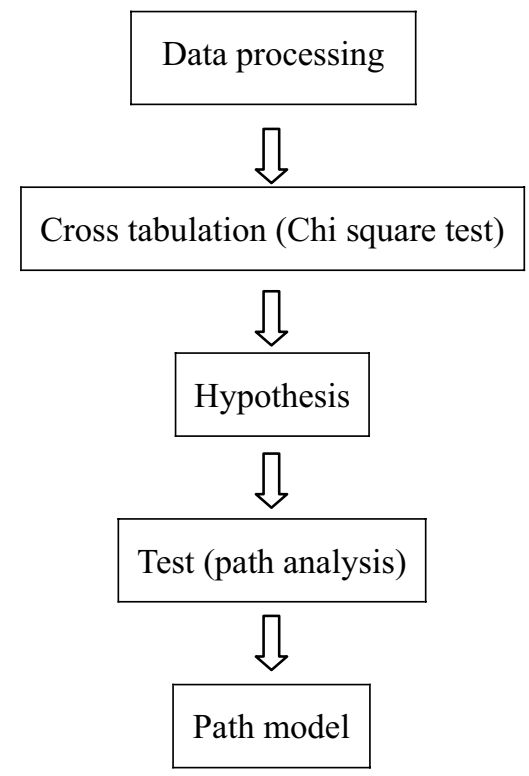

Figure 1. Analysis process 


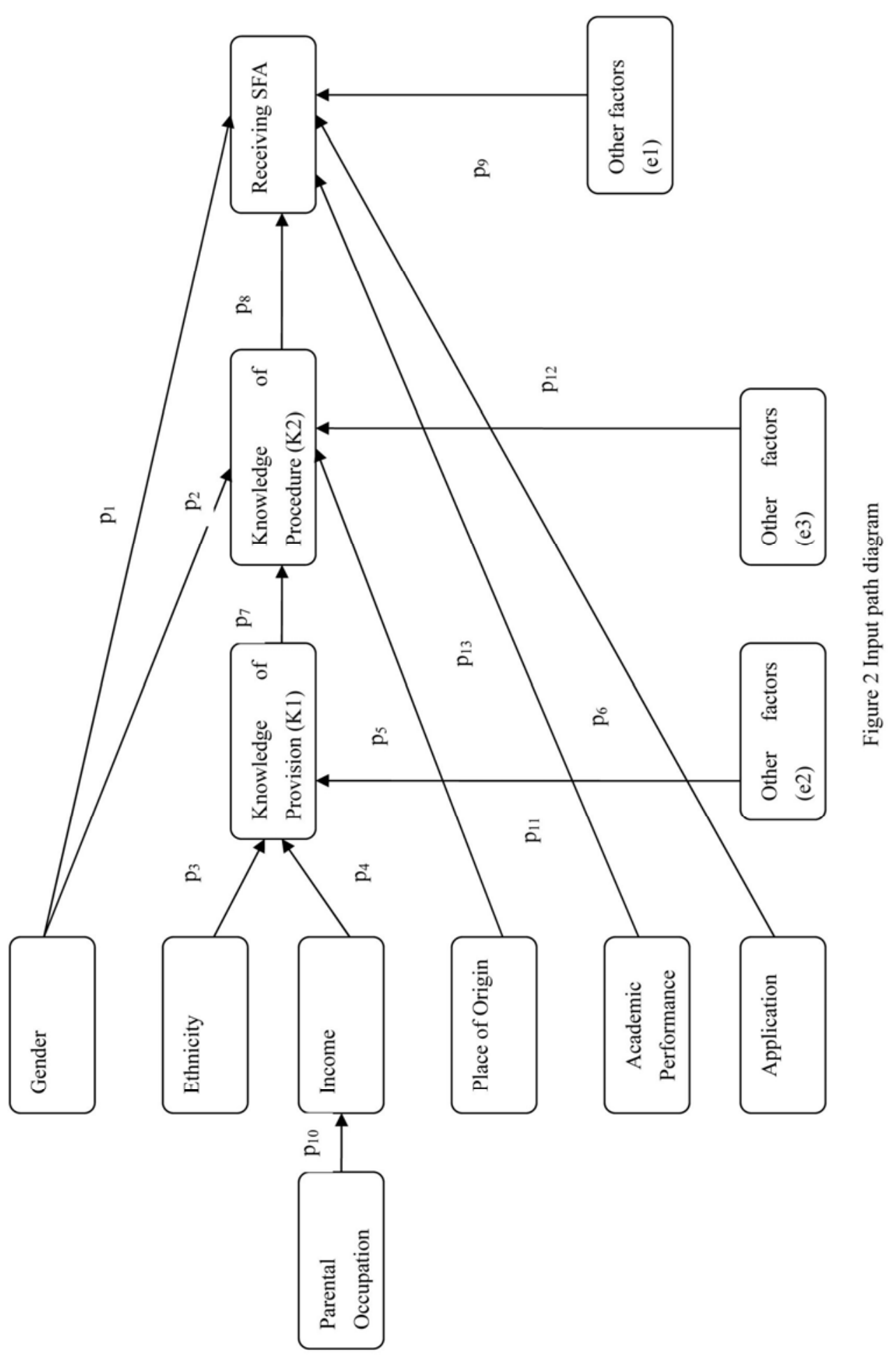




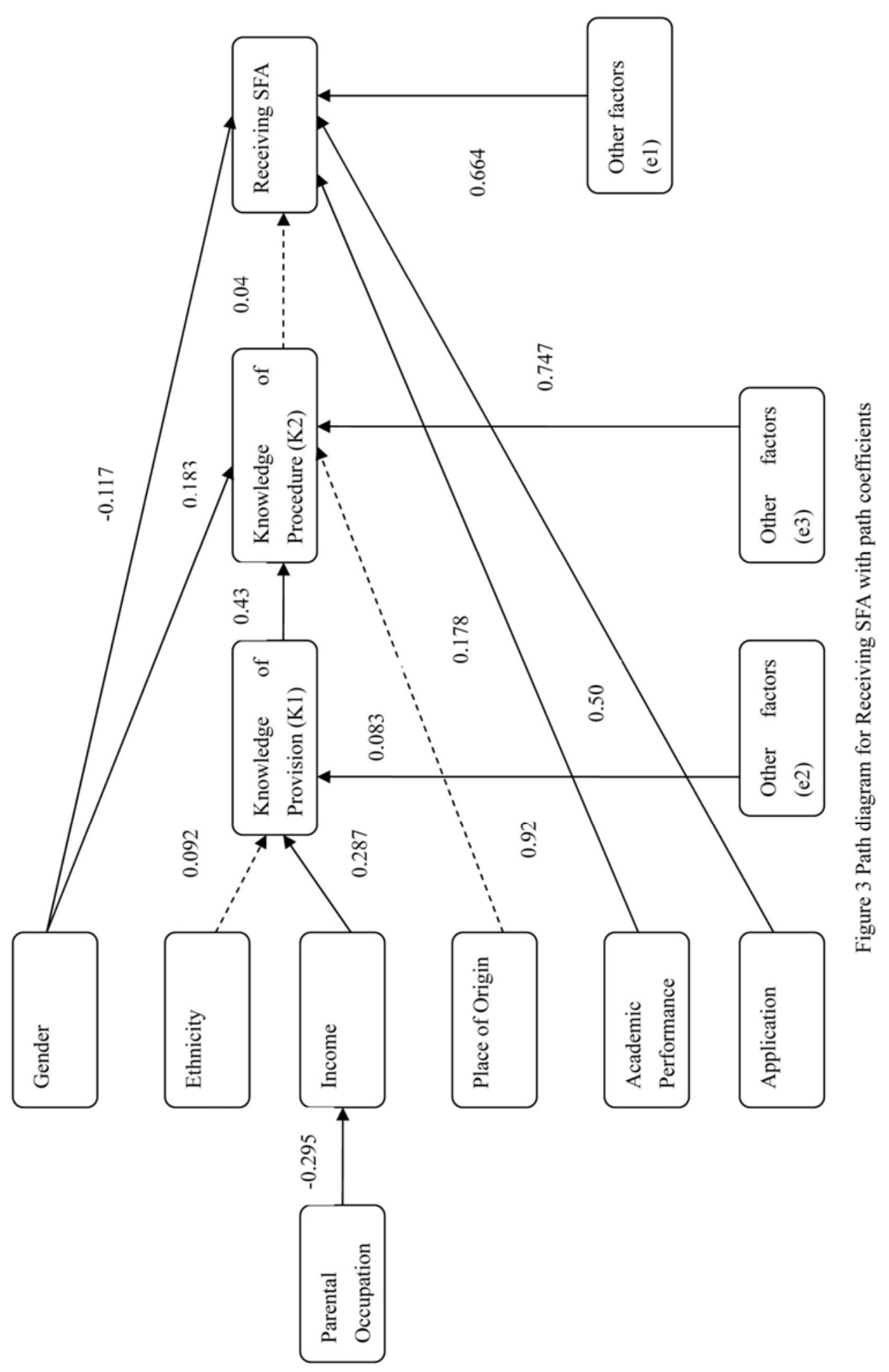

